\title{
Synchronised provisioning at the nest: parental coordination over care in a socially monogamous species
}

Bi-parental care is very common in birds, occurring in over $90 \%$ of species, and is expected to evolve whenever the benefits of enhanced offspring survival exceed the costs to both parents of providing care. In altricial species, where the nestlings are entirely dependent on the parents for providing food until fledging, reproductive success is related to the capacity of the parents to provision the offspring at the nest. The degree to which parents synchronise their visits to the nest is rarely considered by studies of bi-parental care, and yet may be an important component of care, affecting the outcome of the reproductive attempt, and the dynamics of sexual conflict between the parents. Here we studied this aspect of parental care in the long-tailed finch (Poephila acuticauda), a socially monogamous estrildid finch. We monitored parental nest visit rates and the degree of parental visit synchrony, and assessed their effects on reproductive success (e.g. brood size, number of offspring fledged and nestling growth). The frequency of nest visits in a day was low in this species ( $<1 \mathrm{visit} / \mathrm{hour}$ ), but there was a high level of synchrony by the two partners with $73 \%$ of visits made together. There was a correlation between the proportion of visits that were made by the pair together and the size of the brood at hatching, although the level of synchronous feeding was not related to the number of fledglings a pair produced, or the quality of those offspring. We suggest that nest visit synchrony may primarily be driven by the benefit of parents being together whilst foraging away from the nest, or may reduce nest predation by reducing the level of activity around the nest throughout the day. 


\section{Synchronised provisioning at the nest: parental coordination over \\ 2 care in a socially monogamous species}

3 Erica P. van Rooij* \& Simon C. Griffith

4 Department of Biological Sciences, Macquarie University, Sydney, Australia.

5 *Correspondence: S.C. Griffith, Department of Biological Sciences, Macquarie University, NSW

62109 , Australia.

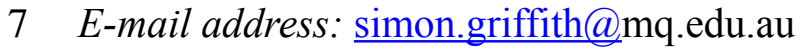

8 Running head; Parental care in the long-tailed finch

9 Word count: 4906

10 Keywords: parental care, nestling provisioning, synchronicity, social monogamy 


\section{ABSTRACT}

12 Bi-parental care is very common in birds, occurring in over $90 \%$ of species, and is expected to

13 evolve whenever the benefits of enhanced offspring survival exceed the costs to both parents of

14 providing care. In altricial species, where the nestlings are entirely dependent on the parents for

15 providing food until fledging, reproductive success is related to the capacity of the parents to

16 provision the offspring at the nest. The degree to which parents synchronise their visits to the nest

17 is rarely considered by studies of bi-parental care, and yet may be an important component of

18 parental care, affecting the outcome of the reproductive attempt, and the dynamics of sexual

19 conflict between the parents. Here we studied this aspect of parental care in the long-tailed finch

20 (Poephila acuticauda), a socially monogamous estrildid finch. We monitored parental nest visit

21 rates and the degree of parental visit synchrony, and assessed their effects on reproductive

22 success (e.g. brood size, number of offspring fledged and nestling growth).

23 The frequency of nest visits in a day was low in this species $(<1 \mathrm{visit} / \mathrm{h})$, but there was a

24 high level of synchrony by the two partners with $73 \%$ of visits made together. There was a

25 correlation between the proportion of visits that were made by the pair together and the size of

26 the brood at hatching, although it was not related to the number of fledglings a pair produced, or

27 the quality of those offspring. We suggest that nest visit synchrony may primarily be driven by

28 the benefit of parents being together whilst foraging away from the nest, or may reduce nest

29 predation by reducing the level of activity around the nest throughout the day. 
30 Key words Biparental care, nestling provisioning, long-tailed finch, Poephila acuticauda,

31 cooperative behaviour INTRODUCTION

32 Parental care is common in birds, with bi-parental care occurring in more than $90 \%$ of species,

33 and expected to evolve whenever the benefits of enhanced offspring survival exceed the costs to 34 both parents of providing care (Clutton-Brock 1991): Royle et al. 2012). In altricial species,

35 where the nestlings are entirely dependent on the parents for food until fledging, reproductive

36 success is often limited by parental feeding rates (Royle et al. 2006). However, provisioning

37 involves energy expenditure by the parents, which may have a negative effect on their future

38 reproduction through trade-offs with survival (Nur 1988) or attractiveness (Griffith 2000). Since

39 each partners' own future potential might be enhanced if the other parent contributed more of the

40 total investment in offspring, there is an interesting conflict between the sexes (Trivers 1972;

41 McNamara et al. 2003).

42 Studies of socially monogamous birds have provided good opportunities to explore the

43 evolutionary dynamics at the heart of this social bond between male and female partners (Royle

44 et al. 2002). Over the past couple of decades, possibly because of the interest in sexual conflict

45 suggested by Triver's (1972) classic paper, much of the research into bi-parental care has focused

46 on the sources of variation in the level of care provided by individual males and females,

47 particularly in the context of theoretical ideas such as the good-parent hypothesis (Hoelzer 1989),

48 and the differential allocation hypothesis (Burley 1988). These hypotheses and much of the work

49 that has followed (Royle 2002) has focused on the different investment strategies of males and

50 females and the conflict between the sexes. Across all socially monogamous avian species, there

51 is great variation in the level of relative investment by males and females with great inequity in

52 nestling provisioning rates by the two sexes in some species (Sanz \& Tinbergen 1999; Bulit et al.

53 2008), while in others investment is more equitable (Tremont \& Ford 2000; Royle et al. 2006;

54 Lee et al. 2010). 
In contrast to the focus on sexual conflict, rather less work has focused on the strategies

56 through which parents enhance cooperation and coordination of their common goal (the

57 production of offspring in the short- or long-term). Although widely neglected by those studying

58 socially monogamous species with biparental care, those studying cooperatively breeding birds

59 have understandably devoted more effort to understanding the more cooperative elements of

60 parental care. For example, in several cooperatively breeding avian species synchronized feeding

61 visits by helpers-at-the-nest have been observed and discussed (Doutrelant \& Covas 2007;

62 McDonald et al. 2008; Raihani et al. 2010; Nomano et al. 2013). A number of adaptive

63 explanations for this coordination have been proposed, such as a reduction in activity around the

64 nest to reduce exposure to predators (Raihani et al. 2010); signaling of investment to other group

65 members (Doutrelant \& Covas 2007; McDonald et al. 2008; Nomano et al. 2013); to enhance the

66 distribution of food amongst offspring (Shen et al 2010); or improve information amongst parents

67 (Johnstone \& Hinde 2006). Alternatively, it may be that the coordination of chick feeding visits

68 to the nest is just a by-product of normal social foraging or movement behavior to increase

69 efficiency and reduce predation risk, as is often seen in such social species (Lee et al. 2010;

$70 \quad$ Sorato et al. 2012).

71 Although the social coordination of parental care in bi-parental socially monogamous

72 species has been widely neglected, a few relatively recent papers indicate the potential

73 importance of this aspect of parental investment. The benefits of collaborative tactics between

74 partners have been identified in nest site selection (Stamps et al. 2002); through the speed at

75 which egg laying is initiated (Adkins-Regan \& Tomaszyki 2007); and overall reproductive success

76 (van der Pol et al. 2006; Mariette \& Griffith 2012). Several of these studies have indirectly

77 looked at pair coordination by assuming that partners that have prior experience with each other

78 are likely to be more coordinated. In addition, a couple of studies have shown directly that the

79 behavioural compatibility of a male and female has an important effect on reproductive success 
80 (Spoon et al. 2006; Schuett et al. 2011), underlying the importance of considering the pair as a

81 whole in addition to just the characteristics of the individuals involved.

82 Whilst good parental care can be achieved by two individuals working more or less

83 independently (but contributing to the common goal of investing in the brood), recent work has

84 found that in some species with bi-parental care, the male and female are very coordinated in

85 their behavior. For example in a recent study of the zebra finch (Taeniopygia guttata), male and

86 female typically visited the nest relatively few times throughout the day but with a high degree of

87 synchrony, both visiting the nest together (Mariette \& Griffith 2012). Furthermore, during

88 incubation in the zebra finch, both the male and female frequently acted as a sentinel for their

89 partner while he/she was in the nest, warning of approaching danger (Mainwaring \& Griffith

90 2013). Such cooperative and coordinated aspects of parental care have been very rarely reported

91 in socially monogamous species with bi-parental care. The fact that such things have only very

92 recently been reported in the zebra finch, which is one of the intensively studied species with

93 respect to parental care (Griffith \& Buchanan 2010), perhaps illustrates the extent to which this in

94 a neglected area of research. It is now important to investigate the nature of the social bond in

95 additional species with bi-parental care and consider the cooperative aspects as well as the areas

96 of evolutionary conflict to redress the potential-bias that has existed over the past few decades

97 (Roughgarden 2012).

98 Here we present one of the first detailed investigations of the coordination of parental care in

99 a socially monogamous passerine with biparental care - the long-tailed finch (Poephila

100 acuticauda). The long-tailed finch is an endemic Australian estrildid finch that is ecologically

101 similar to the zebra finch although it inhabits the tropical savannah in the north of Australia,

102 rather than the more arid open country that is home to the zebra finch (Higgins et al. 2006).

103 Long-tailed finches are primarily granivorous, but supplement their diet with small invertebrates

104 (Higgins et al. 2006), particularly during breeding. They are socially monogamous and pair 
105 bonds in this species are strong and durable (Zann 1977; van Rooij \& Griffith 2011). They

106 preferentially nest in cavities and breed readily in artificial nest-boxes (van Rooij \& Griffith

107 2011). Both the male and female contribute equally to nest building and the incubation of the

108 eggs (van Rooij \& Griffith 2011), but to date there have been no detailed descriptions of offspring

109 provisioning behaviour. Therefore, here we describe parental nest visit rates and visit synchrony

110 in this species and examine potential effects on breeding success, nestlingand the development

111 and condition of nestlings. We also investigated the extent to which visit rate and synchrony were

112 predicted by social factors such as breeding density and the duration of the pair bond. The

113 formerBreeding density might influence the alternative opportunities that breeding-individuals

114 have to forage socially with other adults breeding nearby (Lee et al. 2010), with). The duration of

115 the tatter providing some indieationpair bond will reflect the level of previous breeding

116 experience with the current partner (van der Pol et al. 2006).2006) and this may affect their

117 degree of behavioural coordination.

\section{METHODS}

\section{Study Area and Species}

120 During the breeding season of 2009 (early March till late September), data was collected on longtailed finches breeding near Wyndham, in north west Australia (S15³3’38’, E12808'59”). This study was approved by the Macquarie University Animal Ethies Committee (\#2007/038), and theWestern Australia Department of Envirenment and Conservation (no. BB 002563). All of the pairs in this study nested in boxeswooden nestboxes that were erected to facilitate the study of both Gouldian finch (Erythrura gouldiae) and long-tailed finches in this area (see Brazill-Boast et al. 2011; van Rooij and Griffith 2011). Adults were caught with hand nets on their nests or

127 using mistnets at creeks and water holes near nesting sites. All adult birds were banded with an 128 individually numbered metal band (supplied by the Australian Bird and Bat Banding Scheme) 
129 and individual colour combinations, and a blood sample was taken from the brachial vein. Adult

130 long-tailed finches are only slightly dimorphic but all birds studied here had been sexed using a 131 molecular marker as part of an earlier study (van Rooij \& Griffith 2010). Pairs can raise multiple

132 broods per season, with brood size varying from two to seven chicks $(4.3 \pm 1.0)$ being

133 provisioned in the nest for a period of about $20.6 \pm 2$ days (van Rooij \& Griffith 2011). Fifty five

134 banded pairs were studied in total with 28 pairs (51\%) making only one recorded breeding

135 attempt, 14 pairs (25\%) having two, and 13 pairs making three breeding attempts (24\%). We

136 counted eggs and inspected nests daily at the predicted end of incubation period to count the

137 number of hatchings. Nestlings were individually marked two days after hatching by clipping the

138 end of one of the claws on their toes and subsequently monitored until they fledged. At the age of

139 ten days all nestlings were banded, measured and weighed and a small blood sample was taken

140 from the brachial vein and stored in ethanol. Nestlings were also measured (mass and tarsus) on

141 day 16 (just before fledging). Nestling measures of day 16 were used as a measure of offspring

142 quality, and we assessed the size difference (in mass) between nestlings as a percentage

143 difference between smallest and largest offspring, to determine the extent to which parents

144 produced a brood of even quality, on the assumption that uneven brood quality and partial brood

145 mortality is a sign of poor parental care. We also computed residual mass to account for variation

146 in skeletal size amongst chicks and calculated the difference in condition between the best and

147 the poorest nestling within a brood. BreedingLocal breeding density, for each reproductive

148 attempt, was calculated as the number of active nests in the same area (see below) as the focal

149 nest, over the days on which the young were being provisioned in the active nest. The study was

150 conducted in a nest box breeding population with colonies of breeding birds in patches of suitable

151 habitat that were spatially separated by areas of more open savannah with few mature trees large

152 enough to erect nest boxes or contain natural nest cavities (further details on the study area are

153 given in Brazill-Boast et al. 2011). 
Pair duration was categorised in three ways:- and based on our intensive study of all

156 Griffith 2011): (a) whether the pair bred together before (0 - never recorded breeding together

157 before; 1 recorded breeding together at least once before), (b) the number of seasons a pair had

158 been recorded breeding together $(0,1,2$; including the current season if the pair bred together

159 earlier in the current season) and (c) the number of times the pair had been recorded breeding

160 together over the seasons (range $0-4)$. Both breeding site fidelity and partner fidelity are high in

161 this species (van Rooij \& Griffith 2011). Ages were based on the number of years since an

162 individual was first banded as a nestling or adult and therefore were 'minimum ages' and for 163 breeding adults varied between 1 and 3 years.

\section{Parental nest visit rates}

165 To assess the rate of parental feeding visits we used video cameras (AVC 647 Color IR Camera;

$1661-2 \mathrm{~m}$ from the entrance of the nest box and connected to a hard-drive Archos 605 WIFI), which

167 filmed the entrance of the nestbox. Individual parental identity was scored from the films by

168 E.P.vR.To allow easy individual recognition of the parents when entering the nest, one of the

169 parents was marked with a white dot on the back of the head (correction fluid), two to six days

170 before the parents were filmed-(when they were captured when the chicks were about 6 to 9 days

171 old). Although these marks did wear off within a few weeks, they were usually quite apparent on

172 the films, and we only used data from pairs where the sexes could be readily distinguished in the

173 videos. Birds were acclimated to the presence of the camera over a minimum 24-h period prior to

174 recording. A total of 37 nesting attempts were filmed from 29 independent pairs (29 first breeding

175 attempts; six pairs also on their second attempt and two pairs on their third attempt). The data 
176

177

collected on second and third broods were used in only one analysis comparing later broods to the first brood.

Nests were filmed when nestlings were ten and eleven days old, coinciding with the period of maximal nestling growth. Recording started around 6am (just after sunrise) and continued for around 10 hours per day (total 367 hours filmed; $594 \mathrm{~min} . \pm 74$ min per nest per day). The videos were later analysed using VLC media player, which provided accurate data on timings of behaviour in the video files. The number of visits to the nest by each parent was recorded, along with the timings of each visit and the time spent inside the nest. For rate, the number of visits was divided by the number of hours a particular nest was videoed. Whilst it was not captured in video data (which was focused on a small area around the nest), in the course of our nest monitoring and adult trapping we witnessed over a hundred incidences of adults arriving to the nest tree. Whilst this was not quantified, we also present some anecdotal observations of this behaviour.

\section{Nest visit synchrony}

We considered that males and females were together at the nest (i.e. a synchronous visit) if the second individual to enter the nest did so within 5 minutes of the first individual entering the nest.

Given the very long intervals between visits (see results) we believe that this is justified and suggests that they have arrived at the nest tree in a coordinated way. Using the duration of nest visits and their frequency throughout the day we calculated the probability of temporally coincident visits by two parents working completely independently.

We calculated the proportion of synchronised visits as: (number of visits together $\mathrm{x} 2$ ) / total number of visits by individuals alone. We calculated the likelihood of both parents being at the box together by chance on the basis of the actual time that each individual was present during 
199 the day. We calculated expected time spent at the nest together for each pair separately and

200 compared them with observed proportion of time spent at the nest together with paired t-tests.

\section{RESULTS}

202 There was a positive correlation between the visit rate of the female and male at all nests 203 (Spearman rank correlation $R S=0.611, \mathrm{P}<0.001, \mathrm{~N}=29$ ), with no significant difference

204 between male and female nest visit rate (Paired-samples T-test $\mathrm{T}_{28}=0.351, \mathrm{P}=0.728$ ). Nest visit 205 frequency was low and quite stable over the day with an average of 0.77 ( \pm 0.10 s.d.) individual 206 visits per hour. The nest visit rate was related to the initial brood size $\left(\mathrm{GLM} \mathrm{F} \mathrm{F}_{1,28}=5.90, \mathrm{P}=0.02\right.$;

207 Table 1) and potentially to the hatching success of a clutch (GLM $F_{1,28}=3.76, P=0.06$; Table 1).

208 However, nest visit rate was not related to the condition of a brood, the variance in condition 209 across the brood, the nestingbreeding density or the initiation date of the breeding attempt (Table $1)$.

On average, partners visited the nest together during $73.3 \%$ ( \pm 20.1 S.D.) of visits, which is

212 significantly more than expected by chance (observed proportion of synchronous nest visits vs.

213 the time together at the nest when assuming random nest visit behaviour; paired T-test $\mathrm{T}=$

$214-19.071, \mathrm{P}<0.001, \mathrm{~N}=29$ (see below).i.e. the pair were both found together at the nest more frequently than by chance, calculated using the actual number of minutes that each individual spent at the nest on each day).

217 Overall, parents spent an average of $3 \mathrm{~m} 24 \mathrm{~s}( \pm 8 \mathrm{~m} 36 \mathrm{~s}$ s.d.) in the nest cavity during an 218 individual visit-(visits scored $n=435)$. However there were 28 excessively long visits $(6 \%$ of 219435 visits were over ten minutes in duration), with all other visits being signifieantlysubstantially

220 shorter in duration. Seventeen of these long visits were by females and 11 by males, of which five 221 were by one particular male and were spread throughout the day. It was not clear what the parent 222 was doing in the nest during these extended visits as the nestlings were over ten days old and the 
223 | ambient temperature ranged between 20.6 and 34.9 degrees CeleiusCelsius, suggesting that they

224 are unlikely to have been brooded at this time. When removing these exceptional 28 visits (out of 225 435), the mean time spent inside the nest per visit was $1 \mathrm{~m} 46 \mathrm{~s} \pm 50 \mathrm{~s}$ per visit for males and $1 \mathrm{~m} 41 \mathrm{~s}$

$226 \pm 56$ s (S.D.) for females. These data allow us to calculate the probability of parents being at the

227 nest in the same time, by chance. On average, each parent was present at the nest for

228 approximately 0.067 of the day: 1.46 [average minutes in nest] +5 [minutes spent waiting in tree

229 before or after feeding]) x 7.72 [average number of nest visits per day] / 594 [average minutes

230 filmed per day]. If the parents were working randomly with respect to one another, the likelihood

231 of them both being at the nest at the same time is therefore $0.0045(0.067 \mathrm{x} 0.067)$.

232 Although not quantified, anecdotal observations (during our other nest monitoring work)

233 suggested that parents usually arrived and perched in the nest tree together before the first bird

234 entered the nest. The second bird usually waited outside the nest while the first one went inside,

235 and then when the first bird exited the nest it remained in the nest tree and waited while the

236 second bird was in the nest. When the second bird exited the nest, they both usually flew off

237 together.

238 The proportion of synchronized nest visits by a pair was independent of overall nest visit

239 rate (Spearman rank correlation $\mathrm{RS}=0.204, \mathrm{P}=0.288, \mathrm{~N}=29)$. Five pairs always visited the nest

240 together (17\% of pairs), with, an average of 7.8 synchronous visits per pair across the day. In the

241 other 24 pairs the average proportion of synchronous visits was $66 \%$ with the minimum number

242 of synchronous visits by any pair being 1 out of a total of 11 visits to the nest by both parents.

243 The proportion of synchronized visits by a pair was positively related to the initial brood

244 size at hatching $\left(\mathrm{GLM} \mathrm{F}_{1,28}=7.56, \mathrm{P}=0.01\right.$; Figure 1$)$, but was not related to other estimates of

245 reproductive success: the proportion of eggs that hatched, number of fledglings, variation across

246 the brood in condition (Table 1). 
248 We were unable to identify any determinants of nest visit synchrony with respect to the

249 characteristics of the breeding attempt, pair or the individual males and females. The proportion

250 of synchronous visits was not affected by nesting density or the date on which the reproductive

251 attempt was initiated (Table 1$)$. Nest visit synchrony was not affected by male $\left(\mathrm{F}_{3,28}=0.253\right.$,

$252 \mathrm{P}=0.859)$ or female age $\left(\mathrm{F}_{2,28}=2.049, \mathrm{P}=0.149\right)$. Visit synchrony was not affected by pair bond

253 duration, i.e. whether a pair had bred together before or not $\left(\mathrm{F}_{11,16}=1.417, \mathrm{P}=0.396\right)$, the number

254 of previous seasons in which the pair had bred before $\left(\mathrm{F}_{15,28}=1.462, \mathrm{P}=0.249\right)$ or the number of

255 times the pair had bred together in the current season $\left(\mathrm{F}_{4,28}=1.573, \mathrm{P}=0.214\right)$.

256 A small number of pairs were followed during two $(\mathrm{N}=6)$, or three nesting attempts $(\mathrm{N}=2)$.

257 There was no increase in synchrony between the first and the second recorded breeding attempt

258 (Paired T-test $\mathrm{T}_{5}=-0.463, \mathrm{P}=0.663$; Figure 2). Three of these pairs had bred together before and

259 did not differ in synchrony between the first and second recorded brood (Paired T-test $\mathrm{T}_{2}=0.144$,

$260 \mathrm{P}=0.899)$, the other three pairs had never been recorded as breeding together before but did not

261 show increased synchrony between the first and second brood (Paired T-test $\mathrm{T}_{2}=-1.537, \mathrm{P}=$

262 0.264). For the two pairs that bred three times together, the synchrony of visits on the third

263 attempt was not different to that during the first (Paired T-test $\mathrm{T}_{1}=0.909, \mathrm{P}=0.530$ ) or second

264 (Paired T-test $\mathrm{T}_{1}=1.320, \mathrm{P}=0.413$ ) attempt.

\section{DISCUSSION}

266 In this study of the long-tailed finch we found that nest visits are very infrequent - each partner

267 visited the nest on average less than once an hour - but the individual visit rate was correlated

268 between partners. Furthermore, the male and female typically arrived together (73\% of

269 occasions) and entered the nest individually but one after another. Both the frequency of nest

270 vists and the proportion of synchronised visits are similar to those reported in a couple of other 
271 Australian species. In the crimson rosella Platycercus elegans that feeds its offspring seeds, buds,

272 and fruits, parents visited the nest 0.75 times per hour with $63 \%$ of visits being synchronous

273 (Krebs et al. 1999). In the zebra finch, parents visited the nest 0.96 times per hour with $78 \%$ of

274 visits being synchronised (Mariette \& Griffith 2012). As in other birds that provision offspring

275 with regurgitated food from the crop, nest visit rate in this species, is likely to have been a poor

276 measure of how much food the parents delivered to the nest, because parents can deliver variable

277 amounts of food in a single visit (Krebs et al. 1999; Gilby et al. 2011). As a result we will devote

278 most of our discussion to the temporally coordinated behaviour of the male and female.

279 Variation in the degree of nest visit synchrony by pairs was positively related to the number

280 of chicks that hatched, but was unrelated to all other measures of reproductive success and

281 offspring quality. This might suggest that the degree of synchrony is not primarily about tuning

282 the dynamics of parental care in itself, ascontrary to what has been suggested. For example,

283 Forbes (1993) hypothesised that by visiting together and 'clumping' the distribution of food,

284 parents will be better able to distribute food more equitably amongst their offspring. When food

285 is delivered in a clumped fashion, the most competitive offspring will be overwhelmed and

286 quickly sated by the amount of food available in a short time, ensuring that less competitive

287 offspring are also able to receive some (Forbes 1993). It has also been suggested that by visiting

288 together, parents could increase the information they have about each other, and the needs of the

289 offspring at the end of the provisioning bout, improving the quality of parental care (Johstone \&

Hinde 2006). Further work that could be usefully conducted in this and other species with

synchronised visits to the nest would be to examine the extent to which parents practise strategic

292

feeding positions or the distribution of food to the nestlings when they feed nestlings alone or in

293

concert with one another (Lessells et al. 2006; Smiseth et al. 2003; Dickens \& Hartley 2007).

294 However, although these ideas are certainly worthy of further investigation in this and

295 other species we could no find no support for them in these observations. Neither the overall 
296 | quality of broods or the level of asynchrenyvariance in offspring quality withinacross a brood,

297 were related to the level of coordination by parents. Furthermore, we were unable to identify any

298 predictors of the degree of nest visit synchrony with respect to a number of ecological and pair

299 characters such as how long a pair had apparently been together suggesting that its variation was

300 not driven by familiarity or experience of the partnership as might have been expected (Fowler

301 1995; Black 1996). Whilst coordination of behaviour might be one of the benefits of forming

302 long-term partnerships, it is possible that this can be achieved relatively quickly and may be

303 achieved through the pairing of compatible personalities (Schuett et al. 2011), or through private

304 acoustic duets as seen in the zebra finch (Elie et al. 2010).

305 Long-tailed finch nests are vulnerable to predation and we have directly witnessed

306 predation during the nestling stageof nests by Olive Pythons Liasis olivaceus and Pied

307 Butcherbirds (Cracticus nigrogularis $)$ (van Rooij \& Griffith 2011). Many other nesting attempts

$308(>60 \%)$ in the study area fail to produce any fledglings, but it is difficult to determine the extent

309 to which this is due to predation of nest contents or the result of adult desertion (van Rooij \&

310 Griffith 2011). Nonetheless, it is likely that nest predators account for nests other than the ones

311 that we encountered during the act of predation. As well as predating the chicks these predators

312 are also capable of predating an adult bird that is caught in the cavity nest (which typically only

313 has a single entrance). Synchronised nest visits by parents provide two important routes to

314 reducing predation of the nestlings and the adults themselves. By synchronizing visits, adults will

315 minimise the number of occasions throughout the day when there is activity and loud chick

316 begging calls around the nest (Raihani et al. 2010). A pair that deliver all of their food together

317 will halve the number of feeding bouts throughout the day compared to a pair that visit the nest

318 separately. Second, when the two parents visit the nest together (and enter one at a time) then

319 they can effectively look out for one another, with a 'sentinel' outside alerting it's partner inside

320 the nest to any coming predators. In the zebra finch, Mainwaring \& Griffith (2013) identified this 
321 sentineling behavior for the first time in a socially monogamous species and experimentally

322 demonstrated how effective it was at enabling the bird inside the nest to receive advance warning

323 and leave the nest cavity before a predator arrived. Nest visit synchronization is therefore likely

324 to reduce predation of both offspring and adults around the nest. This is a potentially important component that may only effeetaffect a relatively small number of nests each year (and hence not get easily detected by a study such as this), but havinghave catastrophic consequences for the reproductive event and potentially the future success of the adults. Therefore, this mode of selection may be a very strong force acting on coordinated patterns of parental care, even though it would take a larger sample to detect an affect of nest visit synchrony on actual predation rates. coordinated and synchronized activity away from the nest. In the zebra finch the pair associate very closely with one another throughout the day away from the nest and indeed even during periods when they are not breeding (Zann1996; Mariette \& Griffith 2012). Therefore nest visit synchrony could be a side effect of the pair feeding together. Synchronization might be easier for granivorous species because the nature of the food source enables a pair to forgae efficiently next

to one another, compared to predatory species that have to hunt very mobile prey which are more efficiently gathered by individuals hunting alone. We are unable to investigate it here as we have no data on foraging behaviour, however it is possible that foraging patterns relating to local habitat migh explain some of the variation in synchronous nests visits that we see across the pairs in this study.

342 breeding pair that results in a high level of synchronized provisioning visits to the nest. It is likely

343 that this behavior reduces vulnerability of adults and offspring to predation but it may emerge

344 from a high level of synchrony during foraging away from the nest and throughout the year.

345 Either way, our study highlights the importance of considering the cooperative elements of 
346 behavior in socially monogamous species, something that has been neglected over the past few

347 decades in favour of more fashionable ideas about sexual conflict.

\section{ACKNOWLEDGEMENTS}

349 We would like to thank James Brazill-Boast, Sarah Pryke and all volunteers for invaluable

350 assistance in the field.

\section{FUNDING}

352 This study was supported by an ARC-Diseovery Projeet grant awarded to SCG and a Maequarie

353 University Researeh Exeellenee Seholarship to EPvR.

354 | GRANT DISCLOSURES

355 | Australian Research Council grant: \#DP0881019

356 | COMPETHNG INTERESTS

357 | None

358 | AUTHOR CONTRIBUTIONS

359 Erica van Rooij collected the data in the field, processed the video footage, analysed the data, and-

360 eo-wrote the paper.

361 Simon Griffith conceived and designed the study, assisted with the data analysis and eo-wrote-

362 paper.

363 | ANHMAL ETHHCS 
This study was approved by the Maequarie University Animal Ethies Committee (2007/038) and-

\section{REFERENCES}

367 Adkins-Regan E, Tomaszycki M. 2007. Monogamy on the fast track. Biology Letters 3:617368619

369 Black, JM. 1996. Partnerships in birds: the study of monogamy. Oxford: Oxford University 370 Press.

371

372

373

374

375

376

377

378

379

380

381

382

383

384

385

386

387

388

389

390

391

392

Brazill-Boast J, Ran Rovij EPDessmann JK, Davies GTO, Pryke SR, Griffith SC. 2011. Interferenee from long-tailed finehes eonstrains reproduction in Selection of breeding habitat by. the endangered Gouldian fineh. Jout of Anal Eeology 80:39-48Finch (Erythrura gouldiae) at two spatial scales. Ети 111:304-311

Bulit F, Palmerio AG, Massoni V. 2008. Differences in rates of nest-visitation and removal of faecal sacs by male and female White-rumped Swallows. Ети 108:181 - 185

Burley N. 1988. The differential allocation hypothesis: an experimental test. American Naturalist 132:611-628

Clutton-Brock TH. 1991. The Evolution of Parental Care. Princeton: Princeton University Press

Dickens M, Hartley IR. 2007. Differences in parental food allocation rules: evidence for sexual conflict in the blue tit? Behavioral Ecology 18:674-679

Doutrelant C, Covas R. 2007. Helping has signalling characteristics in a cooperatively breeding bird. Animal Behaviour 74:739-747

Elie JE, Mariette MM, Soula HA, Griffith SC, Mathevon N, Vignal C. 2010. Vocal communication at the nest between mates in wild zebra finches: a private vocal duet? Animal Behaviour 80:597-605

Forbes LS. 1993. Avian brood reduction and parent-offspring "conflict". American Naturalist 142:82-117

Fowler GS. 1995. Stages of age-related reproductive success in birds - simultaneous effects of age, pair-bond duration and reproductive experience. American Zoologist 35:318-328

Gilby AJ, Mainwaring MC, Rollins LA, Griffith SC. 2011. Parental care in wild and captive zebra finches: measuring food delivery to quantify parental effort. Animal Behaviour 81:289-295 
393

394

395

396

397

398

399

400

401

402

403

404

405

406

407

408

409

410

411

412

413

414

415

416

417

418

419

420

421

422

423

424

Griffith SC. 2000. A trade-off between reproduction and a condition-dependent sexually selected ornament in the house sparrow Passer domesticus. Proceedings of the Royal Society of London Series B-Biological Sciences 267:1115-1119

Griffith SC, Buchanan K. 2010. The zebra finch: the ultimate Australian supermodel. Emu 110:v-xii

Higgins PJ, Peter JM, Cowling SJ. eds 2006. Handbook of Australian, New Zealand and Antarctic Birds. Volume 7: Boatbill to Starlings. Melbourne: Oxford University Press

Hoelzer GA. 1989. The good parent process of sexual selection. Animal Behaviour 38:10671078

Johnstone RA, Hinde CA. 2006. Negotiation over offspring care - how should parents respond to each other's efforts? Behavioral Ecology 17:818-827

Krebs EA, Cunningham RB, Donnelly CF. 1999. Complex patterns of food allocation in asynchronously hatching broods of crimson rosellas. Animal Behaviour 57:753-763

Lee JW, Kim HY, Hatchwell BJ. 2010. Parental provisioning behaviour in a flock-living passerine, the Vinous-throated Parrotbill Paradoxornis webbianus. Journal of Ornithology 151:483-490

\section{Lessells CM, Poelman EH, Mateman AC, Cassey P. 2006. Consistent feeding positions of} great tit parents. Animal Behaviour 72:1249-1257

Mainwaring MC, Griffith SC. 2013. Looking after your partner: sentinel behaviour in a socially monogamous bird. PeerJ 1:e83

Mariette MM, Griffith SC. 2012. Nest visit synchrony is high and correlates with reproductive success in the wild zebra finch Taeniopygia guttata. Journal of Avian Biology 43:131-140.

McDonald PG, Te Marvelde L, Kazem AJN, Wright J. 2008. Helping as a signal and the effect of a potential audience during provisioning visits in a cooperative bird. Animal Behaviour 75:1319-1330

McNamara JM, Houston AI, Barta Z, Osorno J-L. 2003. Should young ever be better off with one parent than with two? Behavioral Ecology 14:301-310

Nomano FY, Browning LE, Rollins LA, Nakagawa S, Griffith SC, Russell AF. 2013. Feeding nestlings does not function as a signal of social prestige in cooperatively breeding chestnutcrowned babblers. Animal Behaviour 86:277-289

Nur N. 1988. The Consequences of Brood Size for Breeding Blue Tits. III. Measuring the Cost of Reproduction: Survival, Future Fecundity, and Differential Dispersal. Evolution 42:351-362. 
Raihani NJ, Nelson-Flower MJ, Moyes K, Browning LE, Ridley AR. 2010. Synchronous provisioning increases brood survival in cooperatively breeding pied babblers. Journal of Animal Ecology 79:44-52

Roughgarden J. 2012. The social selection alternative to sexual selection. Philosophical Transaction of the Royal Society. London B. 367:2294-2303.

Royle NJ, Hartley IR, Parker GA. 2002. Sexual conflict reduces offspring fitness in zebra finches. Nature 416:733-736

Royle NJ, Hartley IR, Parker GA. 2006. Consequences of biparental care for begging and growth in zebra finches, Taeniopygia guttata. Animal Behaviour 72:123-130. 130.

Royle NJ, Smiseth PT, Kölliker M. 2012. The Evolution of Parental Care. Oxford: Oxford University Press.

Sanz JJ, Tinbergen JM. 1999. Energy expenditure, nestling age, and brood size: an experimental study of parental behavior in the great tit Parus major. Behavioral Ecology 10:598606

Schuett W, Dall SRX, Royle NJ. 2011. Pairs of zebra finches with similar 'personalities' make better parents. Animal Behaviour 81:609-618

Shen SF, Chen HC, Vehrencamp SL, Yuan HW. 2010. Group provisioning limits sharing conflict among nestlings in joint-nesting Taiwan yuhinas. Biology Letters 6:318-321

Smiseth PT, Bu RJ, Eikenaes AK, Amundsen T. 2003. Food limitation in asynchronous bluethroat broods: effects on food distribution, nestling begging, and parental provisioning rules. Behavioral Ecology 14:793-801

Sorato E, Gullett PR, Griffith SC, Russell AF. 2012. Effects of predation risk on foraging behaviour and group size: adaptations in a social cooperative species. Animal Behaviour 84:823834

Spoon TR, Millam JR, Owings DH. 2006. The importance of mate behavioural compatibility in parenting and reproductive success by cockatiels, Nymphicus hollandicus. Animal Behaviour 71:315-326

Stamps J, Calderón-De Anda M, Perez C, Drummond H. 2002. Collaborative tactics for nestsite selection by pairs of blue footed boobies. Behaviour 139:1383-1412

Tremont S, Ford HA. 2000. Partitioning of parental care in the leaden flycatcher. Emu 100:1-11

Trivers RL. 1972. Parental investment and sexual selection. In Sexual selection and the descent of man. (Ed. B Campbell) pp. 1871 - 1971. Chicago: Aldine 
458 van de Pol M, Heg D, Bruinzeel LW, Kuijper B, Verhulst S. 2006. Experimental evidence for a 459 causal effect of pair-bond on reproductive performance in oystercatchers (Haematopus

460 ostralegus). Behavioral Ecology 17:982-991

461 van Rooij EP, Griffith SC. 2010. Are monomorphic species really sexually indistinguishable: no 462 evidence in wild long-tailed finches (Poephila acuticauda). Ethology 116:929-940

463 van Rooij EP, Griffith SC. 2011. Breeding ecology of an Australian estrildid, the Long-tailed 464 Finch (Poephila acuticauda). Emu 111:297-303

465 Zann R. 1977. Pair-Bond and Bonding Behaviour in three Species of Grassfinches of the Genus 466 Poephila (Gould). Emu 77:97-106

467 Zann RA. 1996. The Zebra Finch: A Synthesis of Field and Laboratory Studies. New York: 468 Oxford University Press 
469 Figure Legends

470 Figure 1 The correlation between brood size (at hatching) and nest visit synchrony in 29 pairs of

471 long-tailed finch parents while feeding their nestlings (Pearson correlation $=0.47, \mathrm{~N}=29, \mathrm{P}=$

472 0.011)

473 Figure 2 Nest visit synchrony in multiple attempts during a season for six pairs. Black lines

474 indicate those pairs that had never bred together before (pair 1-3), grey lines indicate those pairs

475 that had bred together before (pair 4-6) 


\section{Table 1 (on next page)}

Nest visit rate and synchrony of vists in relation to breeding success and environmental factors

Table 1. Overall nest visit rate and nest visit synchrony in relation to breeding success and environmental factors GLM results with overall nest visit rate as response variable in model 1 and nest visit synchrony as response variable in model 2, least significant factors were removed stepwise, displayed here are the values before removing them from the model. 
Table 1. Overall nest visit rate and nest visit synchrony in relation to breeding success and environmental factors GLM results with overall nest visit rate as response variable in model 1 and nest visit synchrony as response variable in model 2, least significant factors were removed stepwise, displayed here are the values before removing them from the model.

\begin{tabular}{|c|c|c|}
\hline & 1. overall nest visit rate & 2. nest visit synchrony \\
\hline brood size & $\mathrm{F}_{1,26}=5.90 ; \mathrm{P}=0.02$ & $\mathrm{~F}_{1,27}=7.56 ; \mathrm{P}=0.01$ \\
\hline number fledging & $\mathrm{F}_{1,25}=0.56 ; \mathrm{P}=0.46$ & $\mathrm{~F}_{1,24}=0.09 ; \mathrm{P}=0.77$ \\
\hline hatch success & $\mathrm{F}_{1,26}=3.76 ; \mathrm{P}=0.06$ & $\mathrm{~F}_{1,26}=2.52 ; \mathrm{P}=0.12$ \\
\hline$\%$ difference nestling mass & $\mathrm{F}_{1,19}=0.47 ; \mathrm{P}=0.50$ & $\mathrm{~F}_{1,18}=0.04 ; \mathrm{P}=0.85$ \\
\hline$\%$ difference nestling condition & $F_{1,20}=0.00 ; P=0.97$ & $F_{1,20}=0.51 ; P=0.48$ \\
\hline nesting density & $\mathrm{F}_{1,18}=0.01 ; \mathrm{P}=0.91$ & $\mathrm{~F}_{1,25}=0.39 ; \mathrm{P}=0.54$ \\
\hline initiation date & $\mathrm{F}_{1,24}=0.37 ; \mathrm{P}=0.55$ & $\mathrm{~F}_{1,19}=0.09 ; \mathrm{P}=0.77$ \\
\hline
\end{tabular}




\section{Figure 1}

Correlation between brood size and nest visit synchrony

Figure 1. Correlation between brood size at hatching and nest visit synchrony

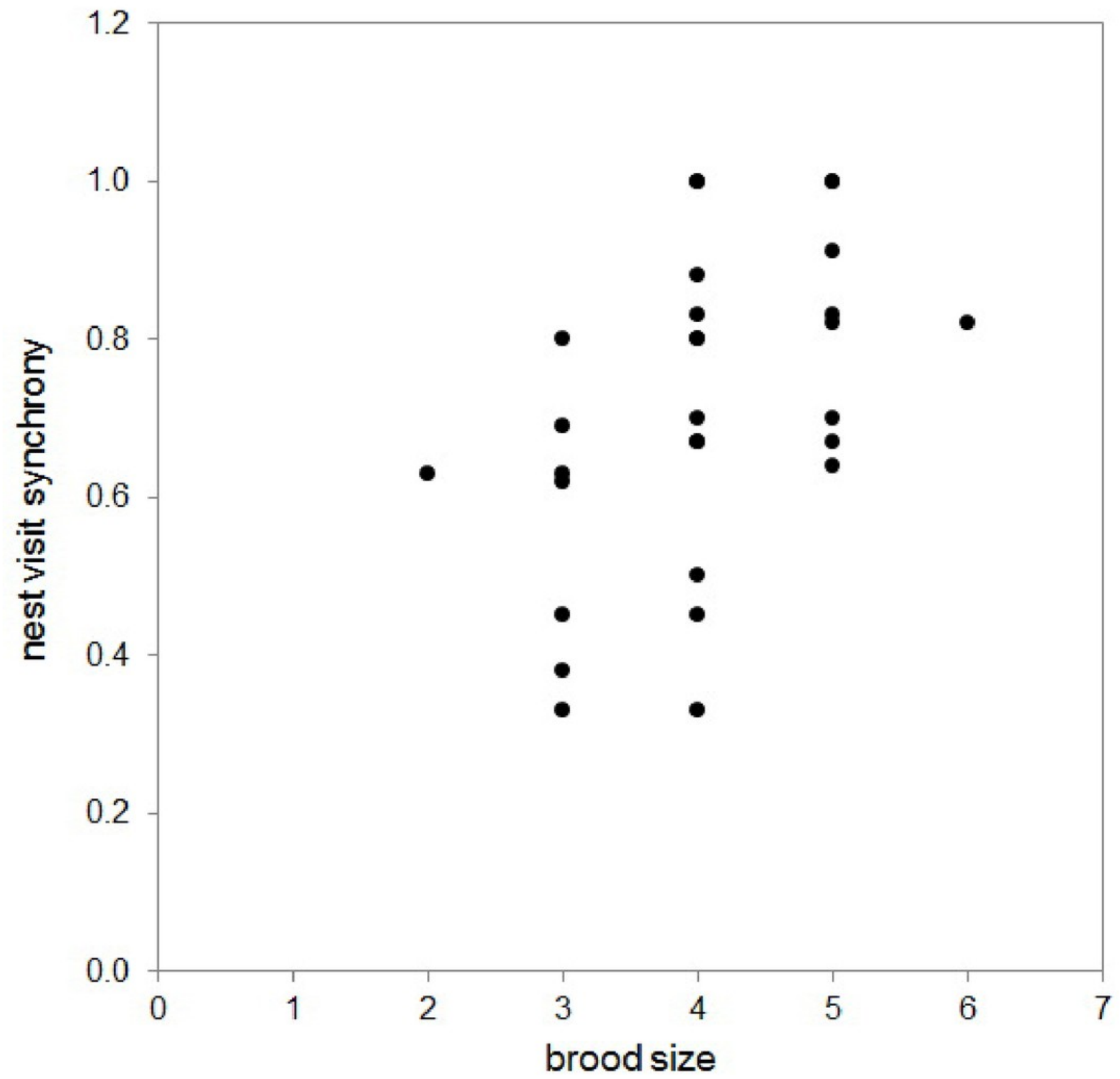




\section{Figure 2}

Nest visit synchrony across multiple attempts within a season

Figure 2. Nest visit synchrony in multiple attempts during a season for six pairs. Black lines indicate those pairs that had never bred together before (pair 1-3), grey lines indicate those pairs that had bred together before (pair 4-6)

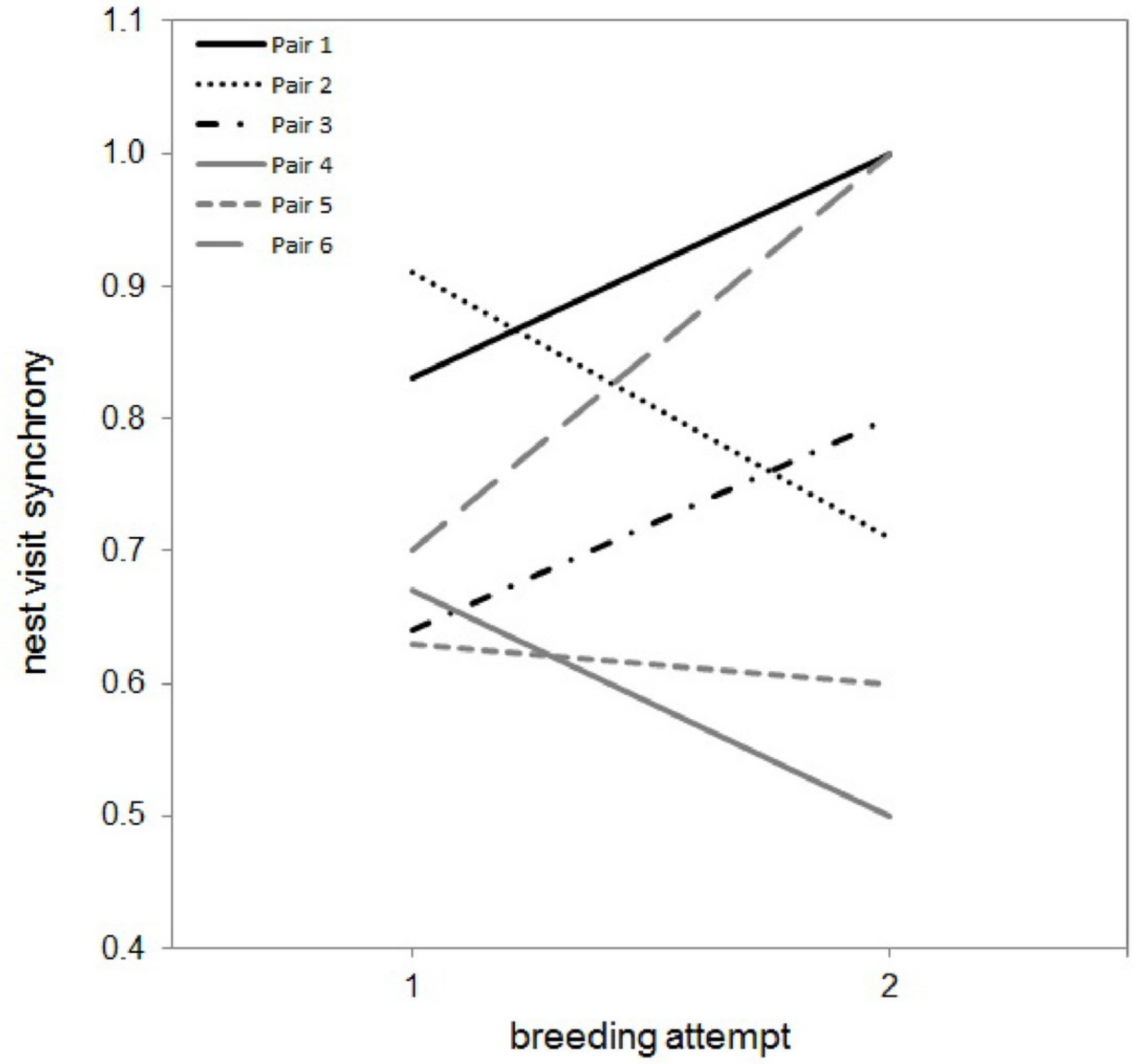

